\section{Rapid Magnesium Chelation as a Method to Study Real-Time Tertiary Unfolding of RNA}

This unit describes a method to measure the unfolding of RNA tertiary structure on a millisecond timescale. A stopped-flow instrument is designed to mix two or more solutions (generally up to four) on a millisecond time scale. After mixing, the resulting solution is moved by a compressed gas into a flow cell for observation (e.g., by UV, CD, or fluorescence spectrometry). Using this methodology, rate constants for unfolding of tertiary to secondary structure can be obtained over a range of temperatures and these values can be used to construct Arrhenius or Eyring plots (Maglott et al., 1999), from which parameters such as activation energy $\left(E_{\mathrm{a}}\right)$, the Arrhenius pre-exponential factor $(A$; Cole et al., 1972; Cole and Crothers, 1972), the enthalpy of activation $\left(\Delta H^{\dagger}\right)$, and the entropy of activation $\left(\Delta S^{\dagger}\right)$ can be obtained (Maglott and Glick, 1997). These data provide information about the energy of the transition state and the energy barriers between secondary and tertiary structure. This information is necessary to be able to predict RNA tertiary structure from secondary structure, since there can be significant kinetic barriers to tertiary folding even if there is only a small energy difference between the secondary and tertiary structures. This procedure requires prior expertise in the use of a stopped-flow spectrophotometer. General information on this subject may be found, e.g., in Fersht (1985).

NOTE: All procedures should be conducted using sterile technique.

NOTE: When handling RNA, suitable precautions should be taken to avoid RNase contamination (see APPENDIX 2A).

\section{MEASUREMENT OF UNFOLDING RATES OF RNA TERTIARY STRUCTURE}

A stopped-flow spectrophotometer is used to measure the rate of unfolding of an RNA tertiary structure that is stabilized by the presence of $\mathrm{Mg}^{2+}$ ions. Unfolding of tertiary structure elements that occurs in the first few milliseconds, as well as at longer time intervals, after removal of the $\mathrm{Mg}^{2+}$ by a chelator (EDTA) can be observed using this methodology.

Stopped-flow instruments are available from a number of vendors, listed below. The most important features are low deadline ( $\leq 2 \mathrm{msec}$ ), microsample volume (e.g., $50 \mu \mathrm{L})$, and the ability for multiple observation techniques (commonly, UV, CD, and fluorescence).

\section{Materials}

EDTA buffer (see recipe) at EDTA concentration needed to chelate all $\mathrm{Mg}^{2+}$ in RNA sample

$\mathrm{Mg}^{2+}$ buffer (see recipe)

Folded RNA sample (see Support Protocol 1)

Syringe filters, $0.22-\mu \mathrm{m}$

10-mL and 3-mL luer-tip syringes (e.g., Fisher)

Parafilm

Stopped-flow spectrophotometer (e.g., Applied Photophysics SX18.MV or equivalent instruments from Olis Instruments or Hi-Tech Scientific)

Side-arm Erlenmeyer flask

BASIC

PROTOCOL

RNA Folding 
Additional reagents and equipment for folding RNA (see Support Protocol 1) and analyzing kinetic traces to determine unfolding rates and activation parameters (see Support Protocol 3)

\section{Prepare solutions}

1. On the basis of pilot experiments, choose a concentration of EDTA that is sufficient to chelate all $\mathrm{Mg}^{2+}$ from the RNA sample during the deadtime of the stopped-flow spectrophotometer.

It is critical that all of the $\mathrm{Mg}^{2+}$ be chelated in the deadtime of the instrument (i.e., before the observation begins). This will always require that EDTA (or whatever chelating agent is used) be present in excess relative to the $\mathrm{Mg}^{2+}$. The way this can be judged is to measure the unfolding rates with increasing amount of EDTA. When the rate does not change, there is enough EDTA. As a check of this, one should compare the total change in absorbance (or whatever physical parameter is being measured) and compare that change to value measured at equilibrium. For absorbance, one would measure (in a normal spectrophotometer) the absorbance of an RNA solution in the presence and absence of $\mathrm{Mg}^{2+}$. The difference should be within error of the value measured as described above.

IMPORTANT NOTE: The [EDTA] needed to fulfill this requirement may vary with the $\left[\mathrm{Mg}^{2+}\right]$ and the deadtime of the instrument. For an instrument with a deadtime of $1.4 \mathrm{msec}$, a 6-fold excess of EDTA to $\mathrm{Mg}^{2+}$ was found to give reproducible results with a high signal-to-noise ratio. Lower EDTA concentrations gave similar kinetic results (rates and activation parameters) with lower signal-to-noise ratios due to the higher $\mathrm{pH}$ differential needed to maintain a constant final pH (Maglott, 1998; Maglott et al., 1998). Experiments should be conducted with a variety of [EDTA]: $\left[\mathrm{Mg}^{2+}\right]$ ratios to help verify that all $\mathrm{Mg}^{2+}$ is being removed during the deadtime of the instrument and that tertiary unfolding is monitored (Maglott and Glick, 1997; Maglott et al., 1998).

2. Filter both the $\mathrm{Mg}^{2+}$ buffer and the EDTA buffer using $0.22-\mu \mathrm{M}$ syringe filters.

3. Degas the EDTA buffer by loading $\sim 6 \mathrm{~mL}$ of the EDTA buffer into a 10 -mL luer-tip syringe, holding a piece of Parafilm over the end of the syringe with a finger, and (holding the syringe tip up) pulling back on the plunger slowly, allowing all air bubbles to move to the top of the syringe. Remove the Parafilm and gently expel all of the air from the syringe. Repeat the procedure 2 to 3 times until the air has been removed.

\section{Set up instrument}

4. Load the degassed EDTA buffer into one of the two drive syringes of the stopped-flow spectrophotometer, being careful not to introduce air bubbles into the drive syringe.

In principle, it does not matter into which of the two drive syringes the EDTA solution is introduced; however, if one of the drive syringes has a larger prime volume than the other on the particular stopped-flow instrument being used, use this drive syringe for the EDTA solution. Then the drive syringe with the smaller prime volume will be used for the RNA solution; thus, less RNA will be required to conduct the experiments.

5. Load $\mathrm{Mg}^{2+}$ buffer into the second drive syringe.

6. Set the wavelength of the stopped-flow spectrophotometer to $268 \mathrm{~nm}$.

The usual RNA absorbance maximum of $260 \mathrm{~nm}$ cannot be used for these experiments because the EDTA buffer absorbs at this wavelength and creates a significant background absorbance. At $268 \mathrm{~nm}$ the absorbance due to the buffer substantially decreases, while the absorbance of the RNA remains sufficient. While this protocol describes the use of hyperchromicity changes to monitor the unfolding of RNA tertiary structure, either fluorescence or circular dichroism could also be used if tertiary unfolding is accompanied by a suitable spectral change. 
7. Acquire 10 to 15 kinetic traces of EDTA buffer versus $\mathrm{Mg}^{2+}$ buffer to fill the observation cell with a blank solution.

This procedure primes the flow line to the cell with the EDTA solution. The number of acquisitions may need to be adjusted depending on the length and volume of the flow lines.

8. Equilibrate the sample cell and the drive syringes of the stopped-flow spectrophotometer at the temperature where the unfolding rate will be measured.

The temperature range over which the unfolding rates will be measured is determined from the stability of both tertiary and secondary structure. In this temperature range, tertiary structure should be adopted in the presence of $\mathrm{Mg}^{2+}$ while in the absence of $\mathrm{Mg}^{2+}$ the secondary structure is stable. Furthermore, the rate of tertiary unfolding must be slow enough at these temperatures to be measured by the particular instrument being used. For yeast tRNA ${ }^{\text {Phe }}$ this range was $28^{\circ}$ to $35^{\circ} \mathrm{C}$ in a $32 \mathrm{mM} \mathrm{Na}{ }^{+}$buffer (Maglott and Glick, 1997) while for unmodified yeast $t R N A^{\text {Phe }}$ the range was $20^{\circ}$ to $32^{\circ} \mathrm{C}$ in a $100 \mathrm{mM} \mathrm{Na}$ buffer (Maglott et al., 1998).

9. Zero the absorbance reading of the blank solution.

Be sure that the lamp has been warmed up and its output has stabilized. Follow the manufacturer's instructions.

\section{Perform unfolding experiment}

10. Remove the $\mathrm{Mg}^{2+}$ buffer from the second drive syringe and load the folded RNA sample (see Support Protocol 1) into the drive syringe.

Degas after folding but before loading into syringe. The RNA solution can be degassed as in step 3, but using a 3-mL luer-tip syringe.

11. Equilibrate both the RNA solution and the EDTA solution (in their respective drive syringes) at the desired temperature for $15 \mathrm{~min}$.

12. Acquire three kinetic traces to prime the line containing the RNA solution.

The number of acquisitions needed to prime the solution in the observation cell may vary with the instrument. See the manufacturer's instructions.

To collect the RNA sample as it is used, have the output line in a small side-arm Erlenmeyer flask. Recovered RNA samples can be checked for degradation by denaturing PAGE, repurified if necessary, and reused by first dialyzing to remove the EDTA and $\mathrm{Mg}^{2+}$ and then dialyzing into the desired $\mathrm{Mg}^{2+}$-containing buffer.

13. At the highest resolution possible, acquire as many kinetic traces as sample quantity allows.

Typically it is desirable to have seven good kinetic traces at each set of conditions. The number of traces obtained from a 1-mL sample will depend on the volume of sample used in each acquisition. To maximize the use of the RNA samples, the lowest possible volume with a reasonable deadtime should be used. For example, with an Applied Photophysics SX18.MV, only $50 \mu \mathrm{L}$ of RNA is needed for a single trace, and the deadtime of this instrument is 1.4 msec.

14. Analyze the kinetic traces (see Support Protocol 3).

\section{FOLDING AND EQUILIBRATION OF RNA SAMPLES}

It is important that the RNA being used in the kinetic experiments be folded into the native tertiary structure. This protocol describes an optimized procedure for folding of both yeast tRNA $^{\text {Phe }}$ and unmodified yeast tRNA ${ }^{\text {Phe }}$. For other RNAs, optimized folding protocols can be developed by changing either the temperature (bath temperature and/or equilibration 
temperature) or the time spent at each temperature to ensure that the RNA has adopted the native tertiary structure.

\section{Materials}

Dialyzed RNA sample (see Support Protocol 2)

$\mathrm{Mg}^{2+}$ buffer (see recipe)

$75^{\circ} \mathrm{C}$ water bath

Spectrophotometer

1. Equilibrate a water bath at $\sim 75^{\circ} \mathrm{C}$.

2. Place a sample of RNA that has been dialyzed into the desired $\mathrm{Mg}^{2+}$ buffer (see Support Protocol 2) in a microcentrifuge tube. Dilute to $1 \mathrm{~mL}$ total volume with additional $\mathrm{Mg}^{2+}$ buffer.

3. Measure the absorbance of the sample at $268 \mathrm{~nm}$ in a regular laboratory spectrophotometer.

The absorbance of the sample should be high enough that the absolute absorbance change observed upon unfolding will be $>0.002 O D_{268}$.

For example, $0.6 O D_{260} / m L$ of yeast $t R N A^{\text {Phe }}$ was used to study tertiary unfolding in a 32 $m M \mathrm{Na}^{+}$buffer (Maglott and Glick, 1997) and the observed absorbance changes were from 4 to $20 \mathrm{mOD}_{268}$ in a temperature range of $28^{\circ}$ to $34^{\circ} \mathrm{C}$. More RNA can be used, but the background absorbance will increase as well.

4. Place the closed microcentrifuge tube into the $75^{\circ} \mathrm{C}$ water bath for $5 \mathrm{~min}$.

5. Remove the sample from the water bath and equilibrate it at room temperature for 30 min.

The folded RNA cannot be stored and must be used immediately.

SUPPORT PROTOCOL 2

Rapid

Magnesium

Chelation as a

Method to Study

Real-Time

Teriary Unfolding of RNA

\section{FLOW DIALYSIS OF RNA SAMPLES}

This protocol describes a procedure for equilibrium flow dialysis of the RNA sample into the $\mathrm{Mg}^{2+}$ buffer used in the kinetic experiment. Use of this procedure ensures that the total concentration of $\mathrm{Mg}^{2+}$ in the RNA sample is accurately known. The total $\left[\mathrm{Mg}^{2+}\right]$ of an RNA sample that has simply been diluted into the $\mathrm{Mg}^{2+}$ buffer may be influenced by the presence of $\mathrm{Mg}^{2+}$ ions or chelators that are present due to previous handling of the RNA sample (e.g., PAGE purification or ethanol precipitation).

\section{Materials}

$\mathrm{Mg}^{2+}$ buffer (see recipe)

Argon source

Dry RNA sample of interest

Bottle-top filtration apparatus containing a $0.22-\mu \mathrm{m}$ filter (e.g., Corning)

10-well microdialyzer (Spectrum)

Peristaltic pump

Cellulose ester membrane for use with 10-well microdialyzer (Spectrum), MWCO 5000

1. Filter $2 \mathrm{~L}$ of $\mathrm{Mg}^{2+}$ buffer under vacuum using a bottle-top filtration device containing a $0.22-\mu \mathrm{m}$ filter. 
The $\mathrm{Mg}^{2+}$ buffer used in these experiments was designed for unmodified yeast $t R N A^{\text {Phe }}$ to satisfy the requirement that the secondary structure of the tRNA form in the absence of $\mathrm{Mg}^{2+}$ and the tertiary structure form in the presence of $\mathrm{Mg}^{2+}$. For other $R N A s$, the $\left[\mathrm{Mg}^{2+}\right]$ may need to be altered, and the composition of the buffer may also need to be changed to meet the structural requirements of the experiment.

2. Bubble argon gas through the buffer for at least $30 \mathrm{~min}$.

3. Assemble a 10 -well microdialyzer with a peristaltic pump according to manufacturer's instructions using a 5000 MWCO cellulose ester membrane.

This procedure has been optimized for tRNA samples with molecular weights of $\sim 25 \mathrm{kDa}$. For larger or smaller RNAs the MWCO of the membrane may need to be changed.

4. Fill the chamber of the microdialyzer with $\mathrm{Mg}^{2+}$ buffer, being careful not to allow formation of air bubbles under the wells.

Holding the dialyzer at a slant with the buffer inlet at the bottom and the buffer outlet at the top allows the air within the chamber to be forced out of the outlet without allowing air bubbles to become trapped under the wells.

5. Dissolve a dry RNA sample in 100 to $200 \mu \mathrm{L}$ of $\mathrm{Mg}^{2+}$ buffer and transfer the solution to a well of the microdialyzer.

The amount of RNA that can be used in this procedure depends on the amount of RNA needed to conduct the experiments. Both small and large quantities of RNA can be prepared using this procedure; however, if the RNA sample being used already contains a high concentration of salt, the volume of the RNA solution may significantly expand during dialysis and the final concentration of the RNA may be too low to be useful. It is recommended that the samples be desalted by either ethanol precipitation or flow dialysis against TE buffer, pH 7.0 (see APPENDIX 2 A for recipe), followed by ethanol precipitation, to prevent this difficulty.

6. Rinse the tube with another $100 \mu \mathrm{L}$ of $\mathrm{Mg}^{2+}$ buffer and add this solution to the RNA sample in the dialyzer.

7. Dialyze the RNA against the $\mathrm{Mg}^{2+}$ buffer at a flow rate of $5 \mathrm{~mL} / \mathrm{min}$ (controlled by a peristaltic pump).

A slower flow rate may also be used and may be useful for RNA samples containing higher concentrations of residual salts, to prevent significant volume expansion of the solution as it reaches equilibrium in the new buffer system.

8. When $\sim 50 \mathrm{~mL}$ of the $\mathrm{Mg}^{2+}$ buffer remains in the reservoir, change the flow rate to 0 $\mathrm{mL} / \mathrm{min}$. Reserve this buffer for dilution of the sample to the appropriate concentration during the kinetic experiments.

9. Using a micropipettor, remove the RNA solution from the microdialyzer and place into a microcentrifuge tube. Rinse the well of the dialyzer at least two times with $\mathrm{Mg}^{2+}$ buffer and add to the microcentrifuge tube.

10. Use sample immediately or store at $4^{\circ} \mathrm{C}$ for up to $\sim 1$ week.

RNA samples kept in solution for $>1$ week may begin to degrade. It is not advisable to freeze the sample in solution, as repeated freeze-thawing of an RNA sample may also cause degradation.

RNA Folding Pathways

11.7.5 
SUPPORT PROTOCOL 3

\section{DETERMINATION OF TERTIARY UNFOLDING RATES AND ACTIVATION}

PARAMETERS

\section{Materials}

Graphical analysis software (e.g., Kaleidagraph from Synergy Software)

Statistical analysis software (e.g., SAS from SAS Institute)

1. Overlay the individual traces, discarding any that contain artifacts or are particularly different from the majority.

Do not include the kinetic traces obtained while priming the RNA solution.

2. Average these overlaid traces into a single trace.

3. Attempt to fit this average trace (excluding any datapoints collected during the deadtime of the experiment) to a single exponential curve: absorbance $=a \times \exp (-$ rate $\times t$ ), where $a$ is the amplitude of the kinetic trace.

All stopped-flow instruments come with fitting software; see manufacturer's instructions to carry out these steps.

If the process is single-exponential, then the residual to the fit should not show any distinct patterns and should fluctuate between $10^{-4}$ and $10^{-3}$. The best fit is the one that has the lowest residual value.

4. If there is a pattern to the residual (i.e., sinusoidal) or if the residual is large $\left(>10^{-3}\right)$, then repeat the fitting procedure to increasing numbers of exponential components until a good fit is obtained. For example, for a two-exponential fit, absorbance $=a_{1}$ $\times \exp (-$ rate $\times t)+a_{2} \times \exp (-$ rate $\times t)$, where $a_{n}$ is the amplitude of one phase of the kinetic trace.

If the tertiary unfolding kinetics are not single-exponential, then analysis of activation parameters is more complicated and a mechanism for the unfolding must be established.

5. Obtain the standard deviation of the rate of unfolding at each set temperature from the unfolding rates of each of the individual traces used to obtain the average trace.

The rate $(k)$ is the average rate for each temperature obtained from the individual fitted rate data.

During the course of doing individual fits, one may notice that some traces are not of high quality (e.g., with high signal-to-noise ratios or air bubble artifacts). It may be desirable to create an average trace that excludes one or more traces if this occurs. However, if most of the traces contain artifacts, the source of the artifacts should be determined and corrected, and the experiment should be repeated.

6. Construct an Eyring plot, from which transition-state parameters can be obtained, using the rates obtained at several different temperatures. To obtain $\Delta H^{\dagger}, \Delta S^{\dagger}$, and $\Delta G^{\dagger}$, plot $\ln \left[k /\left(k_{\mathrm{B}} T / h\right)\right]$ versus $1 / T$ (where $T$ is expressed in K, degrees Kelvin) and where $k_{\mathrm{B}}=$ Boltzmann's constant and $h=$ Planck's constant. Use the slope of this line, $\Delta H^{\dagger} / R$, and the intercept, $\Delta S^{\dagger} / R$ (where $R$ is the gas constant) to calculate $\Delta G^{\dagger}$, using the relation $\Delta G^{\dagger}=\Delta H^{\dagger}-T \Delta S^{\dagger}$.

The error on $\Delta G^{\dagger}$ can be obtained by calculating the variance on both the slope and the intercept as well as the covariance between the slope and the intercept and using the following equation:

$\operatorname{var}\left(\Delta G^{\dagger}\right)=R^{2}[\operatorname{var}($ slope $)]+(0.298 R)^{2}[\operatorname{var}($ intercept $)]+2 R(0.298 R)($ covar $)$

where var(slope) is the variance on the value of the slope, var(intercept) is the variance on the value of the intercept, and covar is the covariance between the slope and the intercept (Walpole and Myers, 1978). 


\section{REAGENTS AND SOLUTIONS}

Use deionized, distilled water in all recipes and protocol steps. Use $>99 \%$ pure reagents containing $<0.0005 \%$ divalent metal ion impurities. For common stock solutions, see APPENDIX 2A; for suppliers, SEe SUPPLIERS APPENDIX.

\section{Disodium EDTA stock solution, $150 \mathrm{mM}$}

Dissolve $55.8 \mathrm{~g}$ of disodium EDTA in $1 \mathrm{~L}$ of water. Stable for several months at room temperature.

\section{EDTA buffer}

$1.25 \mathrm{~mL}$ of $200 \mathrm{mM}$ sodium cacodylate stock (see recipe; $10 \mathrm{mM}$ final)

$0.15 \mathrm{~mL}$ of $5 \mathrm{M} \mathrm{NaCl}$ (APPENDIX $2 A ; 30 \mathrm{mM}$ final)

$5 \mathrm{~mL}$ of $150 \mathrm{mM}$ disodium EDTA stock (see recipe; $30 \mathrm{mM}$ final)

Dilute to $25 \mathrm{~mL}$ with deionized water

Adjust to $\mathrm{pH} 6.8$ with $\mathrm{HCl}$ or $\mathrm{NaOH}$

Prepare fresh

Alternate EDTA buffers can be made by adjusting the [NaCl] so that the total $\left[\mathrm{Na}^{+}\right]$remains at $100 \mathrm{mM}$. The $\mathrm{pH}$ of the EDTA solution should be adjusted so that upon 1:1 mixing with the $\mathrm{Mg}^{2+}$ buffer the final $\mathrm{pH}$ remains at the $\mathrm{pH}$ of the original $\mathrm{Mg}^{2+}$ buffer.

$\mathrm{Mg}^{2+}$ buffer

$100 \mathrm{~mL}$ of $200 \mathrm{mM}$ sodium cacodylate stock (see recipe; $10 \mathrm{mM}$ final)

$36 \mathrm{~mL}$ of $5 \mathrm{M} \mathrm{NaCl}$ (APPENDIX 2A; $90 \mathrm{mM}$ final)

$50 \mathrm{~mL}$ of $200 \mathrm{mM} \mathrm{MgCl} 2$ stock (see recipe; $5 \mathrm{mM}$ final)

Dilute to $2 \mathrm{~L}$ with deionized water

Adjust to $\mathrm{pH} 6.8$ with $\mathrm{HCl}$ or $\mathrm{NaOH}$

Prepare fresh

$5 \mathrm{mM}$ is the minimum $\mathrm{Mg}^{2+}$ concentration needed to fold the particular RNA described here. The $\mathrm{Mg}^{2+}$ concentration needed to fold a sample will vary with the RNA and must be optimized (see UNIT 6.3, Support Protocol 3).

\section{$\mathrm{MgCl}_{2}$ stock solution, $200 \mathrm{mM}$}

Dissolve $10.2 \mathrm{~g}$ of magnesium chloride hexahydrate in $250 \mathrm{~mL}$ water. Stable for several months at room temperature.

\section{Sodium cacodylate stock solution, $200 \mathrm{mM}$}

Dissolve $32.0 \mathrm{~g}$ of sodium cacodylate in $1 \mathrm{~L}$ of water. Stable for several months at room temperature.

\section{COMMENTARY}

\section{Background Information}

Since the tertiary structures of RNAs are necessary for biological activity, understanding the folded structures of RNAs and the interactions that stabilize them is clearly important. However, knowledge of the final folded structure cannot reveal the processes by which these molecules fold, beginning from a primary nucleotide sequence. Elucidating the energetics involved in folding of an RNA from secondary structure to tertiary structure should enable a better understanding of why one structure forms in preference to another, and may provide insight into conformational changes that occur during biological processes such as protein synthesis, which may involve local unfolding of tertiary structure elements (LeCuyer and Crothers, 1993, 1994). Furthermore, knowledge of the energetics of tertiary structure formation will also enable prediction of tertiary structure from secondary structure. Algorithms are available to predict secondary structures from primary sequence information (Zuker, 1989), and expansion of these algorithms to include prediction of tertiary structure will allow for the construction of RNAs with defined structures and, possibly, defined functions. However, predictions of tertiary structure formation from secondary structure must also include the energy barriers to folding. To fully
RNA Folding Pathways 
understand RNA folding, it is necessary to characterize the structure of the folded RNA, any intermediates on the folding pathway, and the rate-determining transition state.

Relatively little is known about the rates of tertiary folding and unfolding of RNA, particularly on timescales faster than seconds. Recent approaches to investigate tertiary folding have used both the intrinsic properties of native structure to report on folding transitions, such as self-splicing for ribozymes (Jaeger et al., 1993; Emerick and Woodson, 1994; Emerick et al., 1996; Pan and Sosnick, 1997), as well as indirect techniques like oligonucleotide hybridization (Zarrinkar and Williamson, 1994; Zarrinkar et al., 1996), UV cross-linking (Downs and Cech, 1996), and chemical modification (Emerick and Woodson, 1994; Banerjee and Turner, 1995; Chance et al., 1997; Sclavi et al., 1997). However, these methods cannot monitor transitions that occur faster than about several events per minute.

Several stopped-flow mixing techniques have been developed that can monitor folding transitions on the millisecond timescale. For example, conformational changes associated with substrate binding to ribozymes have been monitored using substrates tagged with a fluorescent adduct (Bevilacqua et al., 1992, 1994; Qin and Pyle, 1997). An especially interesting new approach couples rapid folding, initiated by addition of $\mathrm{Mg}^{2+}$, with hydroxyl radical footprinting (Sclavi et al., 1998; UNIT 11.6). This technique assesses regions of an RNA that become inaccessible to hydroxyl radicals as folding proceeds over time. However, generation of the hydroxyl radicals must occur faster than folding, which is achieved by generating the radicals using a synchrotron X-ray source. A more general method follows folding, again initiated by addition of $\mathrm{Mg}^{2+}$ to an RNA void of divalent metals, using UV (UNIT 11.3) and CD (UNIT 11.5) spectroscopies as well as catalytic activity (Pan and Sosnick, 1997). Since tertiary folding of a ribozyme is required for catalytic activity, rates of catalysis are readily correlated to rates of folding. On the other hand, both UV and CD spectroscopy are sensitive to basestacking and base-pairing, interactions that occur in both secondary and tertiary structure formation. However, verification that the spectroscopic signal being monitored arises solely from tertiary structure formation requires determination of the structure of the RNA in both the presence and absence of $\mathrm{Mg}^{2+}$ under the specific conditions (i.e., buffer and temperature) of the experiment.
Temperature-jump (T-jump) relaxation is one of the most general methods to measure unfolding transitions in RNA that occur on a timescale faster than seconds. The T-jump technique involves rapid heating of an RNA solution, and unfolding of the RNA is monitored spectroscopically as the solution establishes an equilibrium at the higher temperature. Much of our understanding of RNA folding comes from the classic work of Crothers (Cole et al., 1972; Yang and Crothers, 1972; Crothers et al., 1974; Crothers and Cole, 1978), Maass (Riesner et al., 1970, 1973; Urbanke et al., 1973, 1975; Coutts et al., 1975), and Biltonen (Levy et al., 1972), who used T-jump to study the folding and unfolding kinetics of transfer RNAs (tRNA). While T-jump is an extremely powerful technique, it does have some limitations. T-jump equipment is expensive and not widely available, current commercial instrumentation uses relatively large sample volumes $(\sim 1 \mathrm{~mL})$, and photobleaching can lead to sample degradation. Furthermore, some conformational changes are not thermally accessible, and these transitions cannot be monitored using T-jump. For example, tertiary folding of the P4-P6 domain of the Tetrahymena ribozyme is in $\mathrm{Mg}^{2+}$ dependent equilibrium (Szewczak and Cech, 1997) and, since unfolding of secondary and tertiary structure tends to be coupled in the presence of $\mathrm{Mg}^{2+}$, the tertiary-secondary unfolding transition is not thermally accessible.

The Basic Protocol describes a simple, noninvasive method to determine the rate and activation parameters associated with unfolding of native RNA tertiary structure. This method exploits the fact that formation of RNA tertiary structure often requires $\mathrm{Mg}^{2+}$ or other divalent metals (Uhlenbeck, 1987; Celander and Cech, 1991; Kazakov and Altman, 1991; Christian and Yarus, 1993; Pyle, 1993; Butcher and Burke, 1994; Laing et al., 1994; Lu and Draper, 1994; Draper et al., 1995; Bassi et al., 1996; Narlikar and Herschlag, 1996), and it entails mixing an RNA solution containing $\mathrm{Mg}^{2+}$ with excess EDTA in a stopped-flow instrument under conditions of temperature and ionic strength where tertiary structure unfolds after chelation of $\mathrm{Mg}^{2+}$. Low-millisecond resolution can be achieved, and the unfolding transition can be observed by standard absorbance measurements. The results presented show that the stopped-flow technique is a robust and versatile method that in principle can be used to examine a range of systems.
Method to

Real-Time

Teriary Unfolding of RNA

11.7.8 


\section{Critical Parameters}

The most important consideration in this experiment is that, in the same buffer system, the tertiary structure of the RNA form in the presence of $\mathrm{Mg}^{2+}$ and the secondary structure of the RNA form in the absence of $\mathrm{Mg}^{2+}$. Secondly, the unfolding of tertiary structure to the secondary structure must be accompanied by a spectroscopic change (e.g., absorbance, fluorescence, or circular dichroism). Finally, the chelation of the $\mathrm{Mg}^{2+}$ by the EDTA must occur completely and irreversibly (the rate of disassociation of $\mathrm{Mg}^{2+}$ from EDTA is 0.55 $\mathrm{sec}^{-1}$ ) within the deadtime of the spectrophotometer so that the rate of the transition observed will reflect only unfolding.

Control experiments should be conducted to verify that the signal change being observed is due to tertiary unfolding. These may include (1) replacing the EDTA solution with a sodium acetate solution of equivalent anionic charge concentration, and (2) decreasing the temperature of the experiment below where tertiary unfolding will occur upon removal of $\mathrm{Mg}^{2+}$. Furthermore, rapid mixing of the $\mathrm{Mg}^{2+}$ buffer with the EDTA buffer should not give rise to any absorbance change at $268 \mathrm{~nm}$.

\section{Troubleshooting}

Table 11.7.1 describes several problems that can arise in the course of tertiary unfolding experiments, along with their possible causes and solutions.
Anticipated Results

The unfolding of the tertiary structure of unmodified yeast tRNA ${ }^{\text {Phe }}$ was characterized by single exponential kinetics with rate constants ranging from $200 \mathrm{sec}^{-1}$ to $900 \mathrm{sec}^{-1}$ over a temperature range of $20^{\circ}$ to $32^{\circ} \mathrm{C}$ (Maglott et al., 1998). There was a $3 \%$ change in absorbance observed upon unfolding of the tRNA. In this temperature range, the Arrhenius and Eyring plots constructed from these data were linear, and activation parameters were obtained with a $\Delta G^{\dagger}$ of tertiary unfolding of $14 \mathrm{kcal} / \mathrm{mol}$. The rate, absorbance change, and activation parameters obtained for a specific RNA will probably vary from the results that the authors have obtained using unmodified yeast tRNA ${ }^{\text {Phe }}$.

\section{Time Considerations}

The kinetic experiments described here can be conducted in a few hours. Preparation of the sample and equilibration take $\sim 45 \mathrm{~min}$. Acquisition of the individual kinetics traces takes only a few minutes. Analysis of the kinetic traces and any subsequent data handling can be done at any time after the data is collected and can take several hours.

Preparation of the RNA sample in the desired buffer using continuous flow dialysis usually takes $6 \mathrm{hr}$, although the time needed to effect complete buffer transfer will vary depending on the concentration and identity of the buffers being exchanged.

Table 11.7.1 Troubleshooting Guide for Tertiary Unfolding Kinetics

\begin{tabular}{lll}
\hline \multicolumn{1}{c}{ Problem } & \multicolumn{1}{c}{ Possible cause } & \multicolumn{1}{c}{ Solution } \\
\hline $\begin{array}{l}\text { No hyperchromic change } \\
\text { observed }\end{array}$ & RNA was not folded & Fold the RNA \\
& $\begin{array}{l}{\left[\mathrm{Mg}^{2+}\right] \text { is not sufficiently high to }} \\
\text { fold the RNA } \\
\text { Tertiary structure does not unfold } \\
\text { at the temperature used to conduct } \\
\text { the experiment }\end{array}$ & Increase $\left[\mathrm{Mg}^{2+}\right]$ in buffer \\
& $\begin{array}{l}\text { Increase the temperature at which } \\
\text { the experiments are conducted }\end{array}$ & \\
& $\begin{array}{l}\text { Dissolved oxygen in the buffers } \\
\text { Artifacts observed in kinetic } \\
\text { traces }\end{array}$ & $\begin{array}{l}\text { Degas all buffer solutions } \\
\text { Particulate in the buffers }\end{array}$ \\
& Residue in the sample cell & $\begin{array}{l}\text { Filter all buffer solutions } \\
\text { with 0.2- } \mu \mathrm{m} \text { syringe filters } \\
\text { Clean the sample cell } \\
\text { following manufacturer's } \\
\text { directions }\end{array}$ \\
& &
\end{tabular}

RNA Folding Pathways

\subsection{9}

Supplement 6 


\section{Literature Cited}

Banerjee, A.R. and Turner, D.H. 1995. The time dependence of chemical modification reveals slow steps in the folding of a group I ribozyme. Biochemistry 34:6504-6512.

Bassi, G.S., Murchie, A.I.H., and Lilley, D.M.J. 1996. The ion-induced folding of the hammerhead ribozyme: Core sequence changes that perturb folding into the active conformation. RNA 2:756-768.

Bevilacqua, P.C., Kierzek, R., Johnson, K.A., and Turner, D.H. 1992. Dynamics of ribozyme binding of substrate revealed by fluorescence-detected stopped-flow methods. Science 258:13551358.

Bevilacqua, P.C., Li, Y., and Turner, D.H. 1994. Fluorescence-detected stopped flow with a pyrene labeled substrate reveals that guanosine facilitates docking of the $5^{\prime}$ cleavage site into a high free energy binding mode in the Tetrahymena ribozyme. Biochemistry 33:11340-11348.

Butcher, S.E. and Burke, J.M. 1994. A photo-crosslinkable tertiary structure motif found in functionally distinct RNA molecules is essential for catalytic function of the hairpin ribozyme. Biochemistry 33:992-999.

Celander, D.W. and Cech, T.R. 1991. Visualizing the higher order folding of a catalytic RNA molecule. Science 251:401-407.

Chance, M.R., Sclavi, B., Woodson, S.A., and Brenowitz, M. 1997. Examining the conformational dynamics of macromolecules with timeresolved synchrotron X-ray footprinting. Structure 5:865-869.

Christian, E.L. and Yarus, M. 1993. Metal coordination sites that contribute to structure and catalysis in the group I intron from Tetrahymena. Biochemistry 32:4475-4480.

Cole, P.E. and Crothers, D.M. 1972. Conformational changes of transfer ribonucleic acid: Relaxation kinetics of the early melting transition of methionine transfer ribonucleic acid (Escherichia coli). Biochemistry 11:4368-4374.

Cole, P.E., Yang, S.K., and Crothers, D.M. 1972. Conformational changes of transfer ribonucleic acid: Equilibrium phase diagrams. Biochemistry 11:4358-4368.

Coutts, S.M., Riesner, D., Römer, R., Rabl, C.R., and Maass, G. 1975. Kinetics of conformational changes in tRNA ${ }^{\text {Phe }}$ (yeast) as studied by the fluorescence of the Y-base and of formycin substituted for the $3^{\prime}$-terminal adenosine. Biophys. Chem. 3:275-289.

Crothers, D.M. and Cole, P.E. 1978. Conformational changes of tRNA. In TransferRNA (S. Altman, ed.) pp. 196-247. MIT Press, Cambridge, Mass.

Downs, W.D. and Cech, T.R. 1996. Kinetic pathway for folding of the Tetrahymena ribozyme revealed by three UV-inducible crosslinks. RNA 2:718-732.
Draper, D.E., Xing, Y., and Laing, L.G. 1995. Thermodynamics of RNA unfolding: Stabilization of a ribosomal RNA tertiary structure by thiostrepton and ammonium ion. J. Mol. Biol. 249:231238 .

Emerick, V.L. and Woodson, S.A. 1994. Fingerprinting the folding of group I precursor RNA. Proc. Natl. Acad. Sci. U.S.A.91:9675-9679.

Emerick, V.L., Pan, J., and Woodson, S.A. 1996. Analysis of rate-determining conformational changes during self-splicing of the Tetrahymena intron. Biochemistry 35:13469-13477.

Fersht, A. 1985. Enzyme Structure and Mechanism, 2nd Ed., p. 122. W.H. Freeman, New York.

Jaeger, L., Westhof, E., and Michel, F. 1993. Monitoring of the cooperative unfolding of the sunY group I intron of bacteriophage T4. J. Mol. Biol. 234:331-346.

Kazakov, S. and Altman, S. 1991. Site-specific cleavage by metal ion cofactors and inhibitors of M1 RNA, the catalytic subunit of RNase P from Escherichia coli. Proc. Natl. Acad. Sci. U.S.A. 88:9193-9197.

Laing, L.G., Gluick, T.C., and Draper, D.E. 1994. Stabilization of RNA structure by Mg ions: Specific and non-specific effects. J. Mol. Biol. 237:577-587.

LeCuyer, K.A. and Crothers, D.M. 1993. The Leptomonas collosoma spliced leader RNA can switch between two alternate structural forms. Biochemistry 32:5301-5311.

LeCuyer, K.A. and Crothers, D.M. 1994. Kinetics of an RNA conformational switch. Proc. Natl. Acad. Sci. U.S.A.91:3373-3377.

Levy, J., Rialdi, G., and Biltonen, R. 1972. Thermodynamic studies of transfer ribonucleic acids. II. Characterization of the thermal unfolding of yeast phenylalanine-specific transfer ribonucleic acid. Biochemistry 11:4138-4144.

Lu, M. and Draper, D.E. 1994. Bases defining an ammonium and magnesium ion-dependent tertiary structure within the large subunit ribosomal RNA. J. Mol. Biol. 244:572-585.

Maglott, E.J. 1998. Structural and kinetic studies of tertiary folding of an unmodified transfer RNA. Ph.D. Thesis, University of Michigan.

Maglott, E.J. and Glick, G.D. 1997. A new method to monitor the rate of conformational transitions in RNA. Nucl. Acids Res. 25:3297-3301.

Maglott, E.J., Deo, S.S., Pryzkorska, A., and Glick, G.D. 1998. Conformational transitions of an unmodified tRNA: Implications for RNA folding. Biochemistry46:16349-16359.

Maglott, E.J., Goodwin, J.T., and Glick, G.D. 1999. Probing an RNA tertiary structure unfolding transition state. J. Am. Chem. Soc. 121:74617492.

Narlikar, G.J. and Herschlag, D. 1996. Isolation of a local tertiary folding transition in the context of a globally folded RNA. Nat. Struct. Biol. 3:701-709. 
Pan, T. and Sosnick, T.R. 1997. Intermediates and kinetic traps in the folding of a large ribozyme revealed by circular dichroism and UV absorbance spectroscopies and catalytic activity. Nat. Struct. Biol. 4:931-938.

Pyle, A.M. 1993. Ribozymes: A distinct class of metalloenzymes. Science 261:709-714.

Qin, P.Z. and Pyle, A.M. 1997. Stopped-flow fluorescence spectroscopy of a group II intron ribozyme reveals that domain 1 is an independent folding unit with a requirement for specific $\mathrm{Mg}^{2+}$ ions in the tertiary structure. Biochemistry 36:4718-4730.

Riesner, D., Römer, R., and Maass, G. 1970. Kinetic study of the three conformational transitions of alanine specific transfer RNA from yeast. Eur. $J$. Biochem. 15:85-91.

Riesner, D., Maass, G. Thiebe, R., Philippsen, P., and Zachau, H.G. 1973. The conformational transitions in yeast tRNA $^{\text {Phe }}$ as studied with tRNA $^{\text {Phe }}$ fragments. Eur. J. Biochem. 36:76-88.

Sclavi, B., Woodson, S., Sullivan, M., Chance, M.R., and Brenowitz, M. 1997. Time-resolved synchrotron X-ray "footprinting," a new approach to the study of nucleic acid structure and function: Application to protein-DNA interactions and RNA folding. J. Mol. Biol. 266:144-159.

Sclavi, B., Sullivan, M., Chance, M.R., Brenowitz, M., and Woodson, S. 1998. RNA folding at millisecond intervals by synchrotron hydroxyl radical footprinting. Science 279:1940-1943.

Szewczak, A.A. and Cech, T.R. 1997. An RNA internal loop acts as a hinge to facilitate ribozyme folding and catalysis. RNA 3:838-849.
Uhlenbeck, O.C. 1987. A small catalytic oligoribonucleotide. Nature 328:596-601.

Urbanke, C., Römer, R., and Maass, G. 1973. The binding of ethidium bromide to different conformations of tRNA: Unfolding of tertiary structure. Eur. J. Biochem. 33:511-516.

Urbanke, C., Römer, R., and Maass, G. 1975. Tertiary structure of tRNA ${ }^{\text {Phe }}$ (yeast): Kinetics and electrostatic repulsion. Eur. J. Biochem. 55:439444.

Walpole, R.E. and Myers, R.H. 1978. Probability and Statistics for Engineers and Scientists, 2nd ed. Macmillan, New York.

Yang, S.K. and Crothers, D.M. 1972. Conformational changes of transfer ribonucleic acid: Comparison of the early melting transition of two tyrosine-specific transfer ribonucleic acids. Biochemistry 11:4375-4381.

Zarrinkar, P.P. and Williamson, J.R. 1994. Kinetic intermediates in RNA folding. Science 265:918924.

Zarrinkar, P.P., Wang, J., and Williamson, J.R. 1996. Slow folding kinetics of RNase P RNA. RNA 2:564-573.

Zuker, M. 1989. On finding all suboptimal foldings of an RNA molecule. Science 244:48-52.

Contributed by Emily J. Maglott and Gary D. Glick

University of Michigan

Ann Arbor, Michigan
RNA Folding Pathways

\subsubsection{1}

